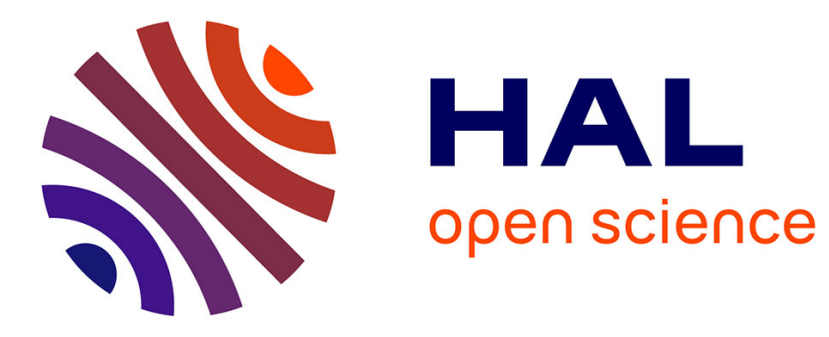

\title{
Investigation of Thermoluminescence Properties of Potential Fibered-OSL Dosimeter Materials
}

\author{
M. Benabdesselam, F. Mady, A. Guttilla, W. Blanc, H. El Hamzaoui, M.
} Bouazaoui, N. Al Helou, J. Bahout, G. Bouwmans, Bruno Capoen

\section{- To cite this version:}

M. Benabdesselam, F. Mady, A. Guttilla, W. Blanc, H. El Hamzaoui, et al.. Investigation of Thermoluminescence Properties of Potential Fibered-OSL Dosimeter Materials. IEEE Transactions on Nuclear Science, 2020, 67 (7), pp.1663-1668. 10.1109/TNS.2020.2971152 . hal-02902686

\section{HAL Id: hal-02902686 \\ https://hal.science/hal-02902686}

Submitted on 6 Jan 2021

HAL is a multi-disciplinary open access archive for the deposit and dissemination of scientific research documents, whether they are published or not. The documents may come from teaching and research institutions in France or abroad, or from public or private research centers.
L'archive ouverte pluridisciplinaire HAL, est destinée au dépôt et à la diffusion de documents scientifiques de niveau recherche, publiés ou non, émanant des établissements d'enseignement et de recherche français ou étrangers, des laboratoires publics ou privés. 


\title{
Investigation of thermoluminescence properties of potential fibered-OSL dosimeter materials
}

\author{
M. Benabdesselam, F. Mady, A. Guttilla, W. Blanc, H. El Hamzaoui, M. Bouazaoui, N. Al Helou, J. \\ Bahout, G. Bouwmans, B. Capoen
}

\begin{abstract}
The luminescence properties of several doped materials are explored in many fields of application, including that of ionizing radiation dosimetry. These luminescence properties are essentially provided by the doping element. In this paper, we report TSL measurements of the trapping and recombination centers involved in the luminescence process of sol-gel derived glasses. Three doped species will be concerned: one transition metal $(\mathrm{Cu})$, one rare-earth element $(\mathrm{Ce})$ and a combination of both in the sol-gel silica matrix. By comparing the performances of these samples according to the criteria required for dosimetry by both TSL and OSL (sensitivity, dose-response, thermal fading), the results show that the simply doped samples really are potential candidates for fibered-OSL dosimetry.
\end{abstract}

Index Terms - Dosimeters, Dosimetry, X-rays, Silica, Irradiation, Thermoluminescence.

\section{INTRODUCTION}

Over the last decades, the use of OSL (optically stimulated luminescence)-based dosimeters has proved to be more attractive compared to the other solutions based on the principle of TSL (thermally stimulated luminescence) or dosimetric films [1] for many technical reasons such as its low cost, the fast reading and the relative simplicity of its implementation.

The development, at the end of the 1980s, of a thermoluminescent material based on alumina single crystal $\left(\mathrm{Al}_{2} \mathrm{O}_{3}: \mathrm{C}\right)$ and known as TLD500, paved the way for the development of a high-performance thermoluminescent

M. Benabdesselam, F. Mady, A. Guttilla and W. Blanc are with the Université Côte d'Azur, CNRS, Institut de Physique de Nice - INPHYNI UMR 7010, F-06108, Nice Cedex 2 France (e-mail: ben@unice.fr, Franck.Mady@unice.fr, a.guttilla@unice.fr, wilfried.blanc@unice.fr).

H. El Hamzaoui, M. Bouazaoui, N. Al Helou, J. Bahout, G. Bouwmans and B. Capoen are with Univ-Lille, CNRS, UMR 8523 - PhLAM - Physique des

Lasers Atomes et Molécules, F-59000 Lille, France (e-mail:

Hicham.Elhamzaoui@phlam.univ-lille.fr, mohamed.bouazaoui@univ-lille.fr, nissrine.alhelou@ed.univ-lille1.fr, jessica.bahout.etu@univ-lille.fr, geraud.bouwmans@univ-lille.fr, bruno.capoen@univ-lille.fr) dosimeter [2] whose physicochemical properties allowed applications in the field of dosimetry. Several years later, the advent of high-power stimulation diodes at different wavelengths, combined to appropriate filters, allowed effective optical stimulation of this single crystal whose intense luminescence has been collected [3]. And from there, OSL dosimetry (OSLD) based on this material, previously used as TSL dosimeter (TLD), was then developed.

OSLD, in particular fibered OSLD, has a major advantage since it does not require any heating of the material up to a few hundred degrees. Such a heat treatment excludes the implementation of fibered-TSLD solutions [4-6].

However, there is a direct correlation between the underlying physics of TSL and OSL processes since these two phenomena are inextricably linked. Both phenomena involve the same charge carrier traps and the same recombination centers. They only differ in the release process of the trapped charges.

This correlation can assist in determining the presence and influence of shallow and deep traps, also in identifying the optically active ones. Note that more than one trap contributes to the OSL signal.

For this reason, many published works about TSL do not only guide the search for OSL materials, but they also contribute to their identification. In other words, TSL experiments can provide useful insight into the OSL process.

Almost all the thermoluminescent phosphors have a more or less important OSL signal but so far, $\mathrm{Al}_{2} \mathrm{O}_{3}: \mathrm{C}$ [7-9] is undoubtedly the most prevalent. However, with current techniques, this material could not be drawn in optical fibers. This study shows, through a TSL approach, that vitreous silica prepared using the sol-gel technique and appropriately doped with active ions $\left(\mathrm{Ce}^{3+}\right.$ and/or $\left.\mathrm{Cu}^{+}\right)$could potentially be excellent candidates for fibered-OSL dosimetry in a radiative environment with several advantages. These doped sol-gel glasses can be produced at low cost, easily connected to a multimode transport fiber and can also be drawn in the form of an optical fiber.

The choice of these doping ions results on the one hand from their high quantum efficiency in the silica matrix and on the other hand, all the results already obtained by other authors on OSL properties of $\mathrm{Cu}$-doped quartz for OSL [10] or scintillating ones of Ce-doped sol-gel silica glasses [11]. 


\section{EXPERIMENTAL DETAILS}

Pure silica xerogels were proposed using the sol-gel route from tetraethylorthosilicate (TEOS) precursor [12]. The obtained xerogels were stabilized at $1000^{\circ} \mathrm{C}$ and then soaked in alcoholic doping solution containing copper or cerium salt. After that, the samples were dried at $50^{\circ} \mathrm{C}$ so as to remove solvents and to retain doping species within the nanopores. The doped samples were then densified in helium atmosphere, as described elsewhere [13-14]. The obtained glasses were drawn to a millimeter-sized rods at a temperature of about $2000^{\circ} \mathrm{C}$. Hence, the studied samples are three colorless doped silica glasses rods with a diameter of about $1.6 \mathrm{~mm}$. Their optical quality seems similar to that of the undoped specimen. For TSL measurements, a piece of each rod was cut and ground. The amount of obtained powder (about $5 \mathrm{mg}$ ) was then spread on an aluminum cupel. The first sample is Ce-doped; the second one is $\mathrm{Cu}$-doped and the third one is $\mathrm{Ce} / \mathrm{Cu}$ codoped. Contents of these doping elements are estimated between 200 and 300 at-ppm.

The TSL signal was recorded in arbitrary units (a. u.) at a linear heating rate of $1^{\circ} \mathrm{C} / \mathrm{s}$ between $\mathrm{RT}$ and $450^{\circ} \mathrm{C}$ by means of a photomultiplier tube (PMT). The emission integration is spanned over a $250-650 \mathrm{~nm}$ spectral range, the delay postirradiation and between the beginning of the TSL reading is usually around two minutes. The spectral distribution of TSL peaks was also achieved from $25^{\circ} \mathrm{C}$ (RT) to $450^{\circ} \mathrm{C}$ by means of an optical multichannel analyzer (OMA), consisting of an optical fiber connected to a spectrograph equipped with a CCD array and an appropriate grating.

For OSL signal recording, the system developed in the laboratory is somewhat different since it is compact and fully fibered. The stimulation is performed with a temperaturestabilized laser diode $(50 \mathrm{~mW}-660 \mathrm{~nm})$ and the detection is achieved by means of a PMT connected to a photon counting unit (Hamamatsu) with appropriate filters. Discriminate between the emitted OSL signal and the stimulation one is done through a dichroic block housing a long pass dichroic mirror and equipped with a fiber adapter on each side. A $2 \mathrm{~cm}$ length sample of the same doped rods as those used in TSL was connected to a multimode pure silica core fiber to guide both OSL and stimulation signals between the dichroic block and the sample.

In both stimulated studies of TSL and OSL, X-ray irradiations have been performed at room temperature (RT). The tube is a $\mathrm{Cu}$ target operating at a voltage of $30 \mathrm{kV}$ (XRG3500 - Inel). For the different doses and dose rates in silica, the irradiation beam is calibrated by means of an ionization chamber (PTWFrance).

To determine the distribution of the trapping levels within the band gap, the Initial Rise (IR) method was deployed by performing a large number of successive (heating/cooling) cycles of the previously irradiated samples [15]. Experimentally, one proceeds by heating the sample at a constant heating rate $\left(\beta=1{ }^{\circ} \mathrm{C} / \mathrm{s}\right)$ until the intensity of the TSL signal reaches at most $10 \%$ of the maximum intensity of the peak. The sample is then cooled down to ambient temperature and warmed up again to $10 \%$ of the maximum etc., until emptying all the traps. By its use, the initial rise method is perhaps the only one that remains applicable when there are overlapping large peaks, as is the case of the amorphous materials studied here.

\section{RESUlts AND Discussion}

\section{A. TSL features and trapping parameters}

Under the same conditions of irradiation and readout, TSL curves relative to the three rods are presented in Fig. 1. Signal intensities are substantially identical, and the curves have been normalized. Depending on the readout temperature, the glow curves can be roughly subdivided into four groups, each consisting of an overlap of several traps: phosphorescence or group I corresponds to the release of carriers from shallow traps. We note that the intensity of this phosphorescence is slightly lower in the case of the $\mathrm{Cu}$-doped sample. Group II designates the ubiquitous peak of silica [1617] while groups III and IV are induced by the dopants. Groups of peaks I and II play an important role in the stability and the storage of the information on the absorbed dose over time and therefore would influence the response of the dosimeter.

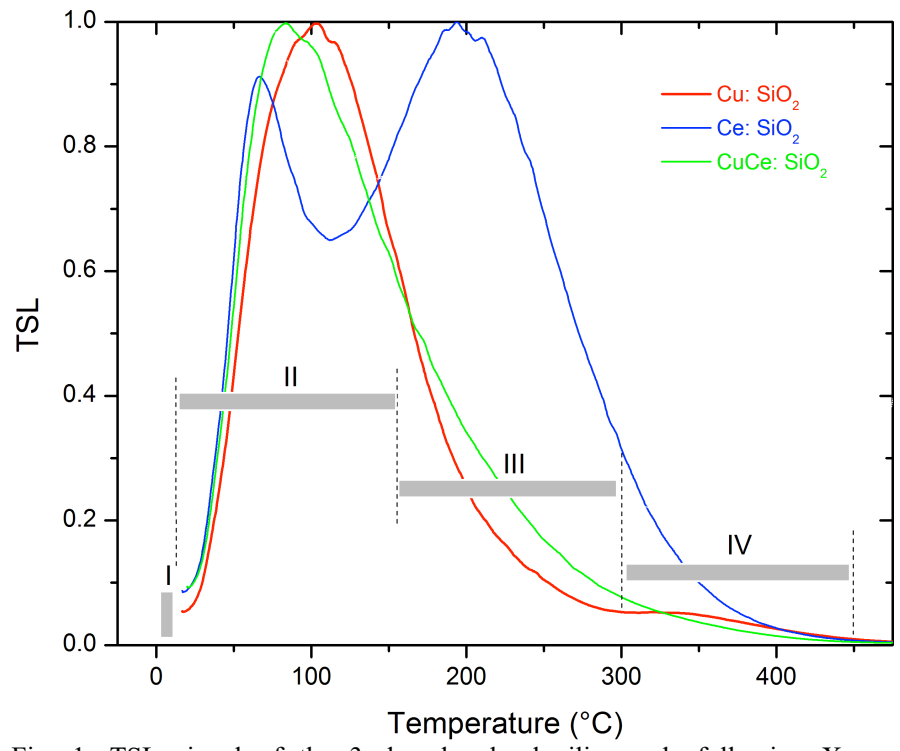

Fig. 1. TSL signal of the 3 doped sol-gel silica rods following X-ray irradiation $\left(330 \mathrm{~Gy}\left(\mathrm{SiO}_{2}\right)\right)$ at $\mathrm{RT}$.

To our knowledge, the origin of all these traps still remains unknown, even though we can say that the set consisting of very shallow traps (corresponding to group I or phosphorescence) and group II are likely inherent to intrinsic defects in the silica matrix like oxygen deficient centers while peaks of groups III and IV might be induced respectively by cerium (group III) and copper (group IV) impurities.

To determine experimentally the trapping parameters corresponding to these TSL peaks, the IR method was applied. According to Randal \& Wilkins [18], TSL intensity is, in a first order approximation, given by (1):

$$
I_{T S L}=s n_{0} e^{-\left(\frac{E}{k T}\right)} \exp \left\{-\frac{s}{\beta} \int_{T_{0}}^{T} e^{-\left(\frac{E}{k T}\right)} d T\right\}
$$

where $s$ is the detrapping frequency factor, $E$ the trap depth, $n_{0}$ the initial concentration of trapped carriers at $t=0, k$ the 
Boltzmann constant, $\beta$ the heating rate and $T_{0}$ the starting temperature.

Garlick \& Gibson [19] demonstrated that, as long as the term $\frac{s}{\beta} \int_{T_{0}}^{T} e^{-\left(\frac{E}{k T}\right)} d T$ is negligible compared to 1 , TSL intensity can be written according (2):

$$
\log I_{T S L}=-\frac{E}{k T}+c t e
$$

By applying the Initial Rise technique between $\mathrm{RT}$ and $250^{\circ} \mathrm{C}$, we obtain on the three samples a quasi-continuous distribution of trapping levels with an estimate of $E$ lying between 0.8 and around $1.5 \mathrm{eV}$ (Fig. 2). This continuum is a specific characteristic of amorphous structures like silica glass, as opposed to the crystalline materials that exhibit discrete trap levels distribution [20]. The obtained activation energy values of the traps have been confirmed theoretically by the calculation of DOTS (Density Of Trapping States) [21].

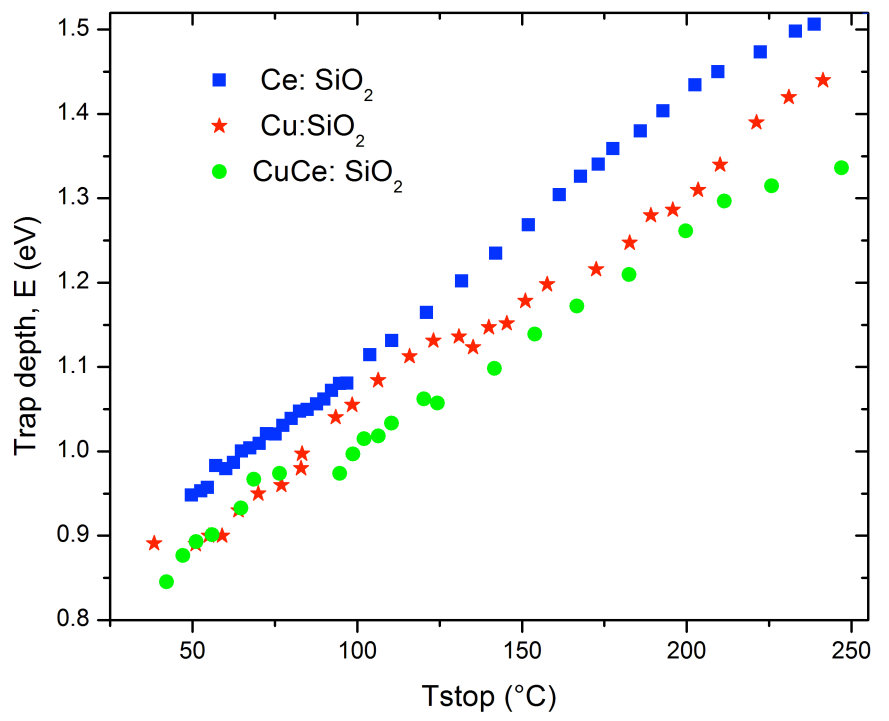

Fig. 2. Activation energy distribution of the traps present in the 3 doped rods.

Fig. 3 corresponds to the representative spectral distributions of TSL peaks. In the case of the Ce-doped sample, we observe a single emission band peaking at $2.64 \mathrm{eV}(470 \mathrm{~nm})$ which has been already assigned to the recombination of trapped electrons involving the $5 \mathrm{~d}^{1} \rightarrow 4 \mathrm{f}^{1}$ transition of $\mathrm{Ce}^{3+}$ ions during the relaxation process $[11,14,22-23]$. The narrow emission band from the $\mathrm{Cu}$-doped sample, located at $2.25 \mathrm{eV}$ $(550 \mathrm{~nm})$, corresponds to the green luminescence of copper and attributed to the $3 \mathrm{~d}^{9} 4 \mathrm{~s} \rightarrow 3 \mathrm{~d}^{10}$ transition of $\mathrm{Cu}^{+}$ions in quartz $[10,13]$. The third and broad band around $2.33 \mathrm{eV}(533$ $\mathrm{nm}$ ) obtained on the $\mathrm{Ce} / \mathrm{Cu}$ co-doped rod, really consists of the contribution of the two previous emissions. Indeed, this large band emission results from the simple superimposition of those of $\mathrm{Ce}$ and $\mathrm{Cu}$ dopants since the addition of the separate emissions seems to reconstitute, at least qualitatively, the emission spectrum of the codoped sample. We can therefore consider that the luminescence emission presented by the codoped sample is a contribution in almost the same proportions of $\mathrm{Ce}^{3+}$ and $\mathrm{Cu}^{+}$ions without any energy transfer.
This could mean that there is no preferential spatial correlation between the trapping defects and the doping ions. The substantially identical luminescence efficiencies of these two ions are in very good agreement with their also identical contents during the synthesis of this codoped sample.

Spectral analyses show that $\mathrm{Ce}^{3+}$ and $\mathrm{Cu}^{+}$ions serve as the recombination centers in the TSL process. A possible mechanism to explain the observed emissions could involve the electrons release from traps (here by heating) which recombine with holes on $\mathrm{Ce}^{3+}$ and $\mathrm{Cu}^{+}$sites. We show below the probable mechanism of relaxation during TSL where $\mathrm{Ce}^{4+}$ and $\mathrm{Cu}^{2+}$ species were formed during irradiation.

$$
\begin{aligned}
& \mathrm{Ce}^{4+}+\mathrm{e}^{-} \rightarrow\left(\mathrm{Ce}^{3+}\right)^{*} \rightarrow \mathrm{Ce}^{3+}+\mathrm{h} v_{470} \\
& \mathrm{Cu}^{2+}+\mathrm{e}^{-} \rightarrow\left(\mathrm{Cu}^{+}\right)^{*} \rightarrow \mathrm{Cu}^{+}+\mathrm{h}_{550}
\end{aligned}
$$

Even if we do not have any information on the origin of the traps giving rise to the TSL peaks, we can however confirm that their nature is of the electron trap type with energy levels spreading continuously between 0.8 and $1.5 \mathrm{eV}$ below the conduction band.

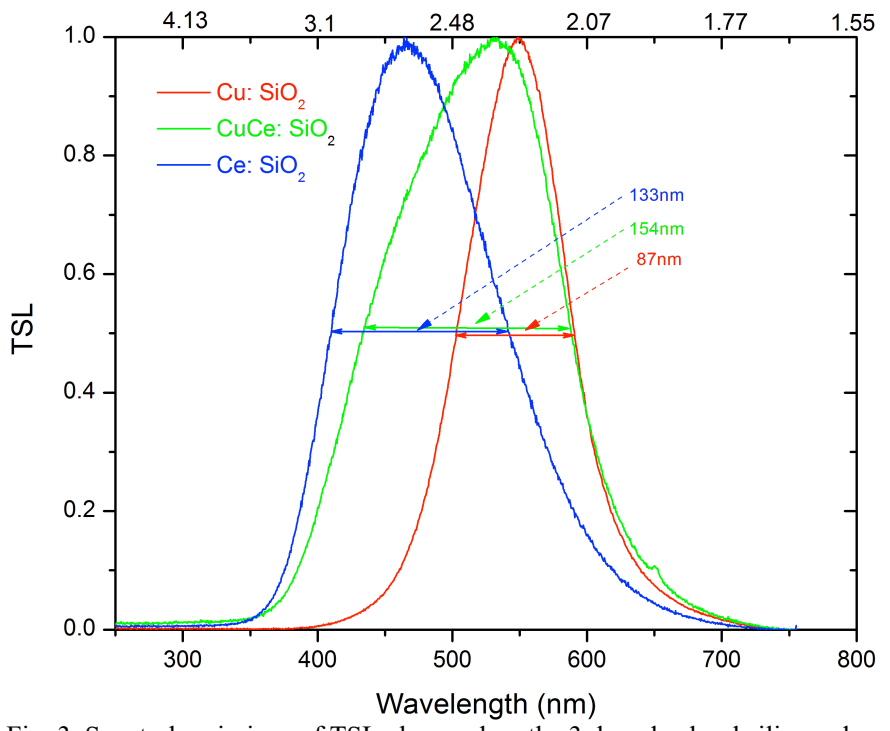

Fig. 3. Spectral emissions of TSL observed on the 3 doped sol-gel silica rods.

Before addressing the dosimetric properties, note that the three presented emissions are intense and spectrally well located since they fall in the middle of the spectral response range of all commercially available UV-Vis PM tubes used in both TSL and OSL dosimetry.

\section{B. Dosimetric Properties by TSL}

Fig. 4 represents TSL response as a function of the dose in silica of the three rods. Up to more than $25 \mathrm{~Gy}$, they all show a linear response, followed by a sub-linear behavior and then saturation. The Ce-doped rod is lightly the most sensitive than the two others which show approximately the same response up to $250 \mathrm{~Gy}$. This response similarity between the $\mathrm{Cu}$-doped rod and the codoped one is not surprising since they have almost the same TSL response (Fig. 1). In addition, these latter samples show a better response linearity than the Ce-doped rod (inset of Fig. 4). 
For the reproducibility test, five successive cycles under the same conditions of irradiation and TSL readout show that measurements are very reproducible with a standard deviation less than $5 \%$ whatever the rod is.

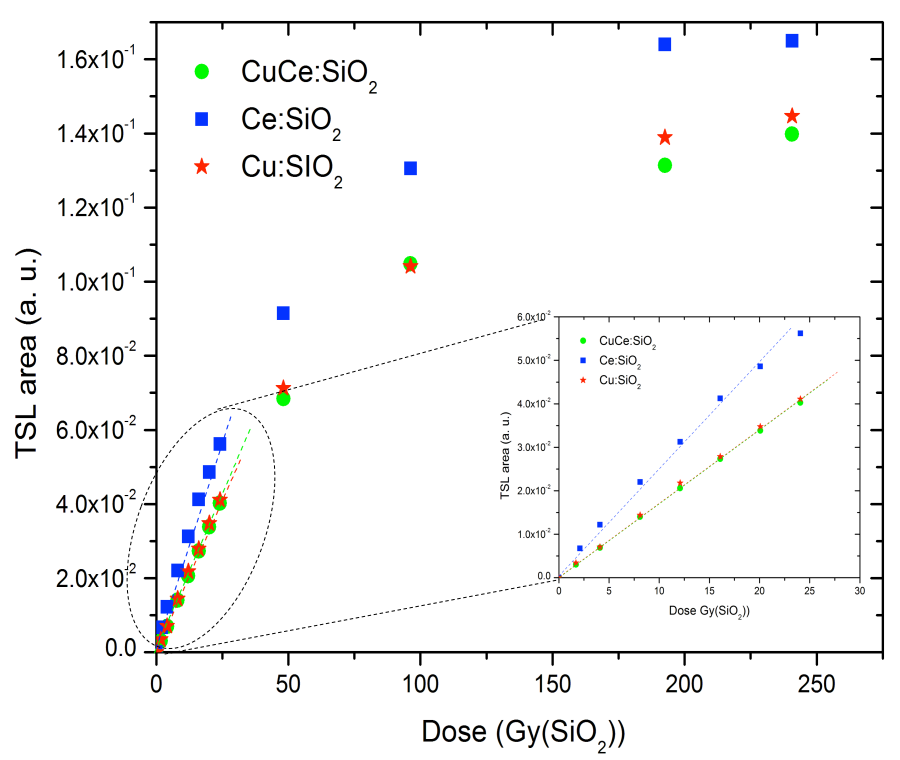

Fig. 4. TSL response as a function of the dose in air, obtained on the Ce- ( $\square)$, the $\mathrm{Cu}-(*)$ and the $\mathrm{Ce} / \mathrm{Cu}-(\bullet)$ doped rods at a dose rate of $2,3 \mathrm{~Gy}\left(\mathrm{SiO}_{2}\right) / \mathrm{s}$. The inset is a zoom of the linear part of the responses up to $30 \mathrm{~Gy}\left(\mathrm{SiO}_{2}\right)$.

Optical sensitivity to the ambient light of the previously irradiated samples is very high since after 10 minutes of exposure, the loss on the dose information by optical bleaching varies between $70 \%$ (Ce-doped) and $80 \%$ (for $\mathrm{Cu}$ doped). This strong sensitivity due to the high ionization cross-section of all the studied samples means that when used as TSL dosimeters, great care should be taken to eliminate any possible exposure of the samples to light as it is the case for the widely used TLD500 dosimeter [24] and on the contrary, this sensitivity makes them potentially very attractive candidates for use in OSL dosimetry.

Fig. 5 shows that these samples are all sensitive to RT thermal fading after irradiation. Indeed, after one-hour storage in total darkness, the loss of information on the absorbed dose is almost $40 \%$ for the 3 rods. This fading rate even reaches $50 \% 24$ hours' post-irradiation. We note, however, that for a short storage time of 10 minutes, the $\mathrm{Cu}$-doped rod retains up to $90 \%$ of the stored dose information while the other two specimens have lost up to $25 \%$ of the signal intensity. This thermal fading is due to the presence in high concentration of intrinsic defects in silica matrix characterized by shallow traps designated by groups I and II shown in Fig. 1 and known to be very unstable at RT. This short-term fading might be important for medical applications but is generally not an issue for personal dosimetry. In all cases, as for other commercial dosimeters, a calibration will necessarily be required before any dosimetric use.

Note, however, that the high radiation sensitivity of the samples combined to their high sensitivity to light because of their large ionization cross-section suggests that when connected to a fibered setup, they could demonstrate a great potential in remote near real-time OSL dosimetry.

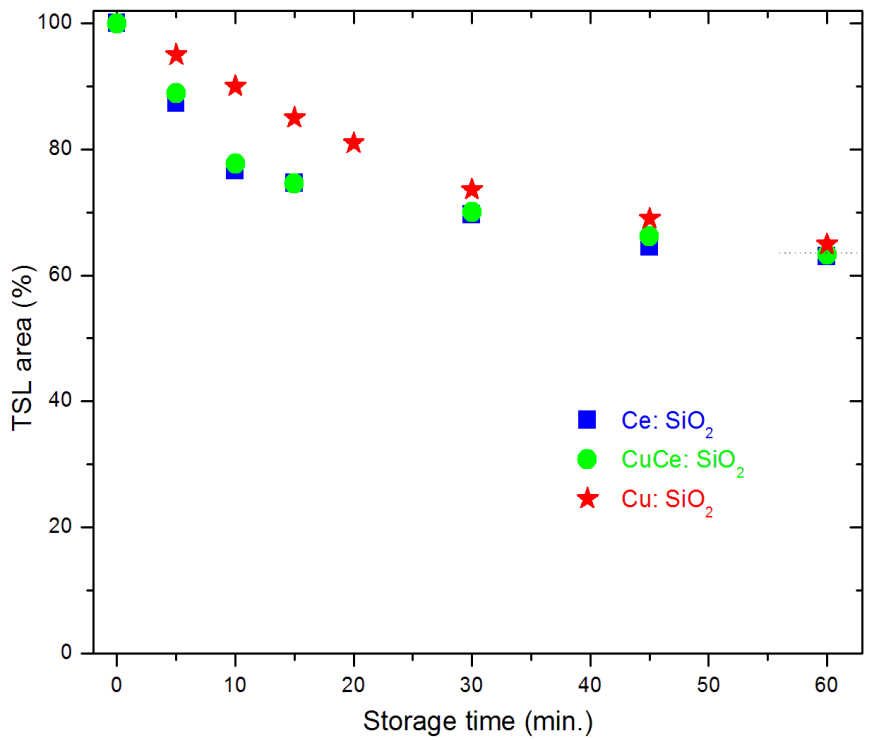

Fig. 5. Fading rate of TSL as a function of storage time in the dark of the Ce$(\square)$, the $\mathrm{Cu}-(*)$ and the $\mathrm{Ce} / \mathrm{Cu}-(\bullet)$ doped rods.

\section{Dosimetric Properties by OSL}

According to the experimental details given in section II, the homemade fully fibred OSL system is shown on Fig. 6. This setup might also be used to record both OSL and radioluminescence $(\mathrm{RL})$ signals [25-26].

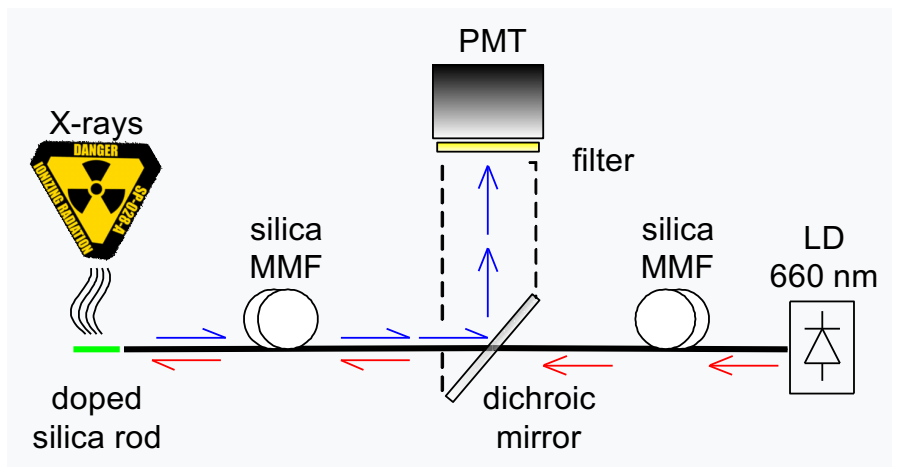

Fig. 6. Schematic representation of the experimental OSL setup.

Whatever the sample, the typical OSL signals obtained just after the end of the radiation at different dose rates resembles that shown in Fig. 7. The integration of the area under the OSL curve is directly correlated to the irradiation dose. By comparison to other doped rods already tested in this study, these three ones show a very intense OSL signal

Fig. 8 represents the OSL response as a function of the dose in silica for the 3 studied samples at a dose rate of 35,36 $\mathrm{mGy}\left(\mathrm{SiO}_{2}\right) / \mathrm{s}$.

At this low dose rate, the OSL responses of $\mathrm{Cu}$ doped sample and especially of the Ce doped one appear to have acceptable linearity at least up to $20 \mathrm{~Gy}(\mathrm{SiO} 2)$ as in TSL whereas that of the codoped specimen becomes sublinear as early as $10 \mathrm{~Gy}$ $\left(\mathrm{SiO}_{2}\right)$. 


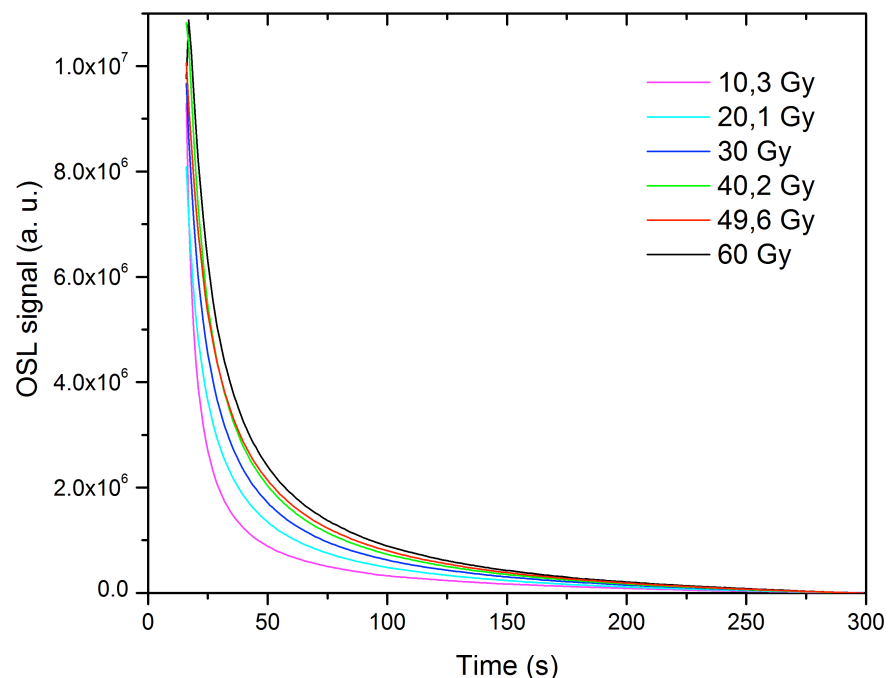

Fig. 7. OSL decay curves for different $\mathrm{X}$-ray dose rate $\left(\mathrm{SiO}_{2}\right)$ of $35,4 \mathrm{mGy} / \mathrm{s}$.

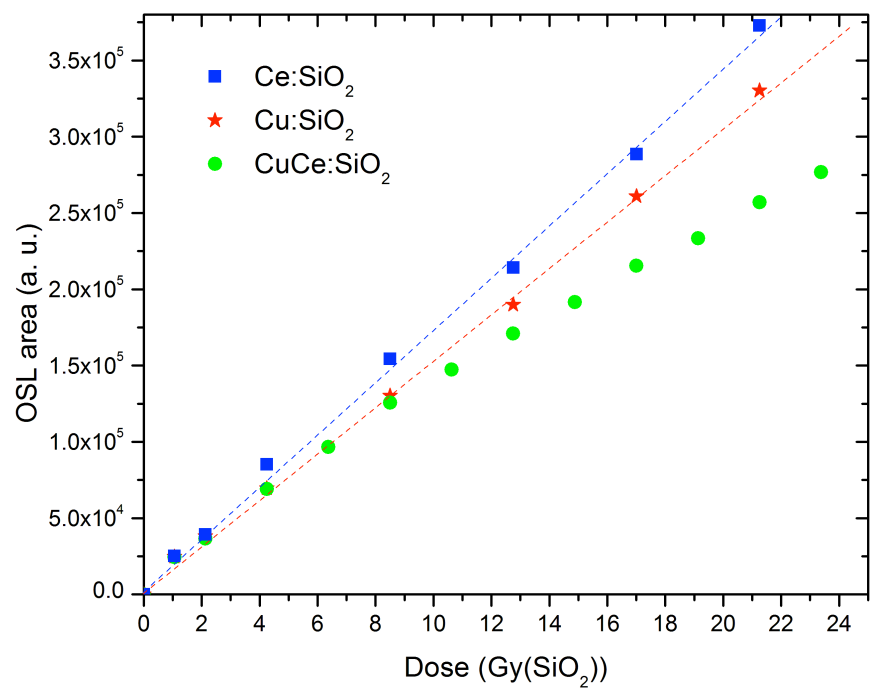

Fig. 8. OSL response as a function of the dose in silica, obtained on the $\mathrm{Ce}$ $(\square)$, the $\mathrm{Cu}-(*)$ and the $\mathrm{Ce} / \mathrm{Cu}-(\bullet)$ doped rods at a dose rate of 35,36 $\mathrm{mGy}\left(\mathrm{SiO}_{2}\right) / \mathrm{s}$.

By performing a comparison in the same range $(0-25 \mathrm{~Gy})$ between the responses as a function of the dose of the three samples through two distinct physical processes of TSL and OSL and under two very different dose rates $(35,36$ $\mathrm{mGy}\left(\mathrm{SiO}_{2}\right) / \mathrm{s}$ and $\left.2,3 \mathrm{~Gy}\left(\mathrm{SiO}_{2}\right) / \mathrm{s}\right)$, we note a remarkable same linear trend for the two simply doped rods $(\mathrm{Ce}$ and $\mathrm{Cu})$ but not for the codoped one. This lack of linearity in the case of the codoped sample is quite possible and is certainly not related to the detection technique used (TSL or OSL) but rather to the dose rate dependence which is likely to exist in the codoped specimen and of whose measurements confirm the nonexistence in the case of the other two samples for a wider dose rate range.

For the other criteria required for OSL dosimetry, the results of Fig. 9 confirm the excellent reproducibility of the signal as in TSL trough six measurements.

Regarding thermal fading at RT, the same rates of decay as those obtained by TSL were observed (around $40 \%$, one-hour post-irradiation). This is quite normal since this loss effect mainly depends on the amount of shallow trapping defects likely to empty their carriers by thermal motion at RT, regardless of the stimulation mode used (TSL or OSL).

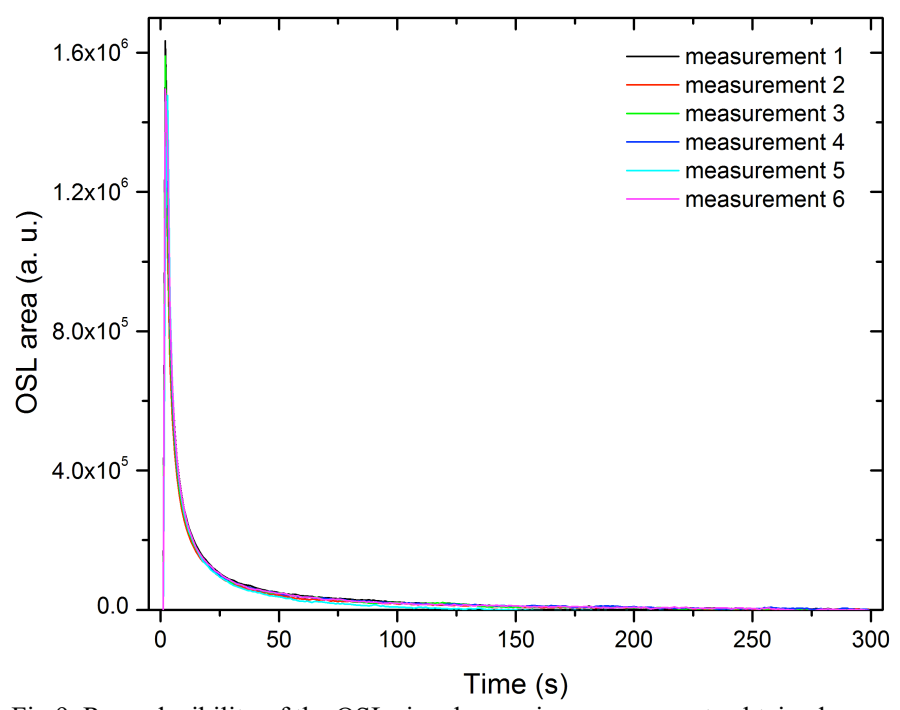

Fig.9. Reproducibility of the OSL signal over six measurements obtained on each tested rod following X-ray irradiation $\left(6 \mathrm{~Gy}\left(\mathrm{SiO}_{2}\right)\right)$ at $\mathrm{RT}$.

\section{CONCLUSION}

The overall results demonstrate that vitreous silica rods prepared using the sol-gel method and doped with active ions are potential candidates as TLDs but also and especially for fibered-OSL dosimetry. TSL approach, whose physical principle mechanism of luminescence is really similar to that of OSL, confirms that the three rods have many assets and fit with the main criteria required by the dosimetry application: a high sensitivity of the response, a visible luminescence emission almost perfectly located, good reproducibility of measurements. In addition, the simply (Ce- or $\mathrm{Cu}$-) doped rods present a quite linear behavior of their responses up to more than 100 Gy where clinical application is concerned, whether in TSL or OSL, without any dose rate dependence. This is very useful for physicists in terms of time saved during routine use. On the other hand, the co-doping does not seem to be beneficial since the codoped sample, unlike the two others, presents a nonlinear OSL response, probably due to a dose rate dependence.

As shown by TSL results, the samples have shallow trapping defects that reduce their ability to store the radiation dose information in the long term (fading), but this can be solved by means of a calibration of the dosimeter with respect to the fading before the first use.

Nevertheless, with their high optical sensitivity and a weak short-term thermal fading, the results showed that the three studied sol-gel silica rods constitute excellent candidates not only as TSL dosimeters but also for a fibered-OSL dosimetry.

Beyond these interesting results, it should be kept in mind that the host matrix of these rods is silica-based. Therefore, unlike other conventional dosimeters, they present a significant advantage since they can easily be drawn in the form of optical fibers for a fibred-OSL dosimetry.

Possible applications are for example the monitoring of the non-accessible radiative areas like nuclear plants or radioactive waste storage centers and in specific applications 
of clinical dosimetry where a high spatial resolution is needed for the improvement of the dose mapping quality.

\section{ACKNOWLEDGEMENTS}

This work was carried out within the operation supported by Andra within the French government "Investissements d'Avenir" program: Surfin Project. This work was also supported by the French Agence Nationale de la Recherche: the LABEX CEMPI (ANR-11-LABX-0007) and Equipex Flux (ANR-11-EQPX-0017); The Ministry of Higher Education and Research, the Hauts-de-France Regional Council and the European Regional Development Fund (ERDF) through the Contrat de Projets Etat-Région (CPER Photonics for Society P4S). This work has also been supported in part by IRCICA institute (www.ircica.univ-lille1.fr) and CERLA platforms of University of Lille.

\section{REFERENCES}

[1] P. Braunlich, D. Schäfer, A. Scharman, "A simple model for TL and TSC of inorganic photoconducting phosphors and experiments pertaining to infra-red stimulated luminescence", Proc. of the $1^{\text {st }}$ Intern. Conf. on Luminescence Dosimetry, Stanford, USAEC, pp. 57-73, 1967.

[2] M.S. Akselrod, V.S. Kortov, D.J. Kravetsky, V.I. Gotlib, "Highly sensitive thermoluminescent anion-defective $\alpha-\mathrm{Al}_{2} \mathrm{O}_{3}: \mathrm{C}$ single crystal detectors", Radiat. Prot. Dosim., vol. 32, no 1, pp. 15-20, 1990

[3] S.W.S McKeever, M.S. Akselrod, and B.G. Markey, "Pulsed optically stimulated luminescence dosimetry using a-Al2O3:C", Radiat. Prot. Dosim., vol. 65, pp. 267-272, 1996.

[4] E.G. Yukihara, S.W.S. McKeever, "Optically Stimulated Luminescence: fundamentals and applications", ISBN 978-0-470-697252, John Wiley \& Sons Ltd, 2011.

[5] L. Botter-Jensen, S.W.S. McKeever, A. G. Wintle, "Optically Stimulated Luminescence Dosimetry", ISBN 0-444-50684-5, Elsevier Science B. V., 2003.

[6] B.L. Justus, S. Rychnovsky, M.A. Miller, K.J. Pawlovich, A.L. Huston, "Optically stimulated luminescence radiation dosimetry using doped silica glass", Radiat. Prot. Dosim., vol. 74, no.3, pp.151-154, 1997.

[7] A.E. Akselrod, M.S. Akselrod, "Correlation between OSL and the distribution of TL traps in $\mathrm{Al}_{2} \mathrm{O}_{3}:$ C", Radiat. Prot. Dosim., vol.100, no. 1-4, pp. 217-220, 2002.

[8] M.S. Akselrod, A.C. Lucas, J.C. Polf, S.W.S. McKeever, "Optically stimulated luminescence of $\mathrm{Al}_{2} \mathrm{O}_{3}$ “", Radiat. Meas., vol. 29, no. 3, pp. 391-399, 1998.

[9] B.G. Markey, L.E. Colyott, S.W.S. McKeever, "Time-resolved optically stimulated luminescence from $\alpha-\mathrm{Al}_{2} \mathrm{O}_{3}: \mathrm{C}$ ", Radiat. Meas., vol. 24, no. 4, pp. 457-463, 1995.

[10] B.L. Justus, K.J. Pawlovich, C.D. Merritt, A.L. Huston, "Optically and thermally stimulated luminescence characteristics of $\mathrm{Cu}^{+}$-doped fused quartz", Radiat. Prot. Dosim., vol. 81, no. 1, pp. 5-10, 1999.
[11] N. Chiodini, M. Fasoli, M. Martini, E. Rosetta, G. Spinolo and A. Vedda, "High efficiency $\mathrm{SiO}_{2}: \mathrm{Ce}^{3+}$ glass scintillators", Appl. Phys. Lett., vol. 81, no. 23, pp. 4374-4376, 2002.

[12] H. El Hamzaoui, L. Courtheoux, V. Nguyen, E. Berrier, A. Favre, L. Bigot, M. Bouazaoui, B. Capoen, "From porous silica xerogels to bulk optical glasses: The control of densification", Mater. Chem. Phys., vol. 121, no. 1, pp. 83-88, 2010.

[13] H. El Hamzaoui, G. Bouwmans, B. Capoen, Y. Ouerdane, G. Chadeyron, R. Mahiou, S. Girard, A. Boukenter, M. Bouazaoui, "Effects of densification atmosphere on optical properties of ionic copperactivated sol-gel silica glass: towards an efficient radiation dosimeter", Mater. Res. Express, vol. 1, 026203, pp. 1-10, 2014.

[14] H. El Hamzaoui, B. Capoen, N. Al Helou, G. Bouwmans, Y. Ouerdane, A. Boukenter, S. Girard, C. Marcandella, O. Duhamel, G. Chadeyron, R. Mahiou, M. Bouazaoui, "Cerium-activated sol-gel glasses for radiation dosimetry in harsh environment", Mater. Res. Express, vol. 3, 046201, pp. 1-7, 2016

[15] N.S. Rawat, M.S. Kulkarni, D.R. Mishra, B.C. Bhatt, C.M. Sunta, S.K. Gupta, D.N. Sharma, "Use of initial rise method to analyze a generalorder kinetic thermoluminescence glow curve", Nucl. Instr. Method Phys. Res. B, vol. 267, no. 20, pp. 3475-3479, 2009.

[16] S.W.S. McKeever, "Thermoluminescence in quartz and silica", Radiat. Prot. Dosim., vol. 8 no. 1, pp. 81-98, 1984.

[17] Y. Mebrouk, F. Mady, J.B. Duchez, M. Benabdesselam, "Colour centers involved in radiation-induced losses of erbium doped aluminosilicate optical fibers", $10^{\text {th }}$ Intern. Symposium on $\mathrm{SiO}_{2}$, Cagliari, Italy, 16-18 June 2014.

[18] J.T. Randall, M.H.F. Wilkins, Phosphorescence and Electron Traps. I. The study of Trap Distributions. Proc. Roy. Soc. A 184 (1945) 365-389.

[19] G.F.J. Garlick, A.F. Gibson, The electron trap mechanism of luminescence in sulphide and silicate phosphors, Proc. Phys. Soc., vol. 60, pp. 574-590, 1948

[20] R. Chen, S.W.S. McKeever, "Theory of Thermoluminescence and Related Phenomena", World Scientific Publishing Co., Singapore, 1997.

[21] F. Mady, M. Benabdesselam, A. Guttilla, "Modeling of the RIA silicabased optical fibers: contribution of the photoionization of radiationinduced trapped states", $12^{\text {th }}$ Intern. Symposium on $\mathrm{SiO}_{2}$, Bari, Italy, 11$13^{\text {th }}$ June 2018.

[22] M.R. Cicconi, D.R. Neuville, W. Blanc, J.F. Lupi, M. Vermillac, D. de Ligny, "Cerium/aluminum correlation in aluminosilicate glasses and optical silica fiber preforms", J. Non-Cryst. Solids, vol. 475, pp. 85-95, 2017.

[23] M. Fasoli, A. Vedda, A. Lauria, F. Moretti, E. Rizzelli, N. Chiodini, F. Meinardi, M. Nikl, "Effect of reducing sintering atmosphere on Cedoped sol-gel silica glasses", J. Non-Cryst. Solids, vol. 355, pp. 1140$1144,2009$.

[24] M. Moscovitch, R.A. Tawil, M. Svinkin," Light induced fading in $\alpha-$ $\mathrm{Al}_{2} \mathrm{O}_{3}$ : C," Radiat. Prot. Dosim., vol. 47, pp. 251-253, 1993.

[25] A.K.M. Mizanur Rahman, H.T. Zubair, Mahfuza Begum, H.A. AbdulRashid, Z. Yusoff, N.M. Ung, K.A. Mat-Sharif, W.S. Wan Abdullah, Ghafour Amouzad Mahdiraji, Y.M. Amin, M.J. Mah, D.A. Bradley "Germanium-doped optical fiber for real-time radiation dosimetry", Radiation Physics and Chemistry, vol. 116, pp. 170-175, 2015.

[26] A.K.M. Mizanur Rahman, Mahfuza Begum, H.T. Zubair, H.A. AbdulRashid, Z. Yusoff, N.M. Ung, D.A. Bradley "Ge-doped silica optical fibers as RL/OSL dosimeters for radiotherapy dosimetry", Sensors and Actuators, vol. 264, pp. 30-39, 2017. 